\title{
Article
}

\section{Ligand-Stabilized Reduced-Dimensionality Perovskites}

Li Na Quan, Mingjian Yuan, Riccardo Comin, Oleksandr Voznyy, Eric M. Beauregard, Sjoerd Hoogland, Andrei Buin, Ahmad R. Kirmani, Kui Zhao, Aram Amassian, Dong Ha Kim, and Edward H. Sargent

J. Am. Chem. Soc., Just Accepted Manuscript • DOI: 10.1021/jacs.5b11740 • Publication Date (Web): 03 Feb 2016

Downloaded from http://pubs.acs.org on February 9, 2016

\section{Just Accepted}

"Just Accepted" manuscripts have been peer-reviewed and accepted for publication. They are posted online prior to technical editing, formatting for publication and author proofing. The American Chemical Society provides "Just Accepted" as a free service to the research community to expedite the dissemination of scientific material as soon as possible after acceptance. "Just Accepted" manuscripts appear in full in PDF format accompanied by an HTML abstract. "Just Accepted" manuscripts have been fully peer reviewed, but should not be considered the official version of record. They are accessible to all readers and citable by the Digital Object Identifier (DOI®). "Just Accepted" is an optional service offered to authors. Therefore, the "Just Accepted" Web site may not include all articles that will be published in the journal. After a manuscript is technically edited and formatted, it will be removed from the "Just Accepted" Web site and published as an ASAP article. Note that technical editing may introduce minor changes to the manuscript text and/or graphics which could affect content, and all legal disclaimers and ethical guidelines that apply to the journal pertain. ACS cannot be held responsible for errors or consequences arising from the use of information contained in these "Just Accepted" manuscripts. 
The rapid advance of organic-inorganic metal halide perovskites represents a breakthrough for nextgeneration thin-film optoelectronics ${ }^{1-6}$. In particular, methylammonium $\left(\mathrm{MA}=\mathrm{CH}_{3} \mathrm{NH}_{3}\right)$ lead iodide $\left(\mathrm{MAPbI}_{3}\right)$ perovskites possess an appropriate bandgap energy ${ }^{7,8}$, large absorption coefficient, and long-range ambipolar photocarrier diffusion ${ }^{9}$. Tremendous efforts from multiple research groups have propelled the certified power conversion efficiency (PCE) of perovskite solar cells to $20.1 \%{ }^{10}$

Unfortunately, perovskite materials lack long-term stability under ambient operation conditions. This has been ascribed, with the aid of theoretical studies, to the low formation energy of MAPbI ${ }_{3}{ }^{11}$. This challenge has motivated efforts to improve device stability, and progress in this direction has been made by developing novel device architectures ${ }^{12}$.

Here we focus instead on the stability of the active material itself. We investigate, using theory and experiment, the origins of instability in conventional $\mathrm{MAPbI}_{3}$; and we propose and fabricate enhanced perovskites - taking advantage of the versatile physical chemistry of this materials system - that constitute low-dimensional hybrid organic-inorganic crystalline thin films. There exist prior reports of two-dimensional (2D) layered perovskites, crafted using bulkier organic molecules in place of methylammonium, that exhibit enhanced stability; however, these suffer from poor photovoltaic performance ${ }^{13}$. The PCE is still lower than $5 \%$ due to their low absorption coefficient and poor carrier transport ${ }^{14}$, and this has hindered their further application. Here, we develop and investigate a platform of mixed-organic, dimensionallytuned quasi-2D perovskite thin films that continuously bridge the gap between $2 \mathrm{D}$ and $3 \mathrm{D}$ materials $\mathrm{s}^{15,16}$. We find that members of the quasi-2D family combine the enhanced stability of $2 \mathrm{D}$ perovskites with the excellent optoelectronic parameters, including long-range photocarrier diffusion, of $3 \mathrm{D}$ perovskites. Our approach relies on computational methods to unravel the origins of instability in conventional $\mathrm{MAPbI}_{3}$, while complementary studies of the physical and optoelectronic properties of quasi-2D perovskites allow us to identify optimized conditions to design and fabricate chemically-stable, high-efficiency photovoltaic devices.

The intermediates between $3 \mathrm{D}$ and $2 \mathrm{D}$ are layered perovskites systematically synthesized by introducing a large organic cation, phenylethylammonium $\left(\mathrm{PEA}=\mathrm{C}_{8} \mathrm{H}_{9} \mathrm{NH}_{3}\right)$, at a judiciously-chosen stoichiometry. This cation possesses a large ionic radius which is incompatible with a $3 \mathrm{D}$ perovskite structure; therefore, perovskites based on this 
cation tend to crystallize into a layered, 2D dimensional structure $^{17}$. Consequently, we can continuously tune the dimensionality of metal halide perovskite compounds by mixing stoichiometric quantities of lead iodide $\left(\mathrm{PbI}_{2}\right)$, methylammonium iodide $\left(\mathrm{CH}_{3} \mathrm{NH}_{3} \mathrm{I}\right)$, and phenylethylammonium iodide (PEAI) to yield compounds with different layer $(n)$ values in the series $\mathrm{PEA}_{2}\left(\mathrm{CH}_{3} \mathrm{NH}_{3}\right)_{n}$ ${ }_{1} \mathrm{~Pb}_{\mathrm{n}} \mathrm{I}_{3 \mathrm{n}+1}$ (table $\mathrm{S} 1$ ). In this notation, the limit $n=\infty$ corresponds to the cubic ${ }_{3} \mathrm{D}$ perovskite, $\mathrm{CH}_{3} \mathrm{NH}_{3} \mathrm{PbI}_{3}$, while the other $\mathrm{n}$ values describe $2 \mathrm{D}(n=1)$ or quasi-2 $\mathrm{D}(n>1)$ perovskite structures (Figure. 1a).
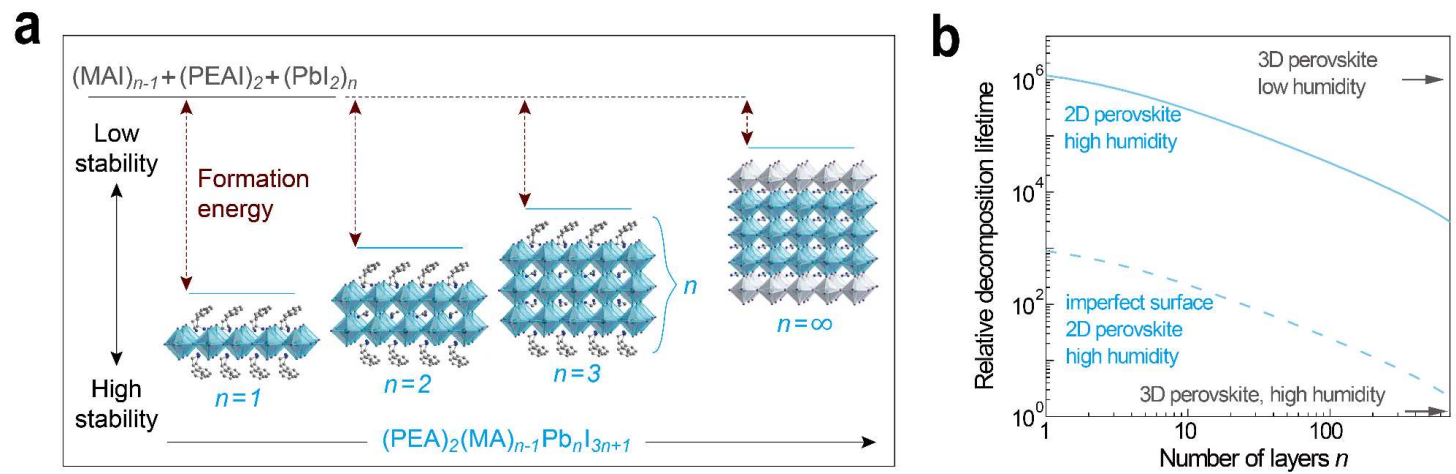

Figure 1. Energetics of perovskite formation and stability. (a) Unit cell structure of $\left(\mathrm{C}_{8} \mathrm{H}_{9} \mathrm{NH}_{3}\right)_{2}\left(\mathrm{CH}_{3} \mathrm{NH}_{3}\right)_{n-1} \mathrm{~Pb}_{n} \mathrm{I}_{3 n+1}$ perovskites with different $n$ values, showing the evolution of dimensionality from $2 \mathrm{D}(n=1)$ to $3 \mathrm{D}(n=\infty)$. (b) DFT simulation of the formation energy of perovskite with different $n$ values in different atmospheres

We investigated the stability of dimensionally-tuned perovskites using density functional theory (DFT) simulations. Calculations show that the conventional $3 \mathrm{D}$ perovskite is marginally stable relative to decomposition into bulk $\mathrm{PbI}_{2}$ and MAI constituents (see details for DFT Simulations in Supporting Information Figure S1), and indeed both components have been observed in thermal gravimetric analysis ${ }^{18}$. However, this process cannot happen within the bulk spontaneously and needs to start from the surface where molecules have sufficient freedom to rearrange. We further analyze the formation enthalpy into that of constituent layers, predicting $\sim 0.55 \mathrm{eV}$ per molecule required to recrystallize MAI layer and $\sim 0.6 \mathrm{eV}$ gain upon conversion of the $\mathrm{PbI}_{2}$ layer (see details on DFT simulations and results discussion in the Supporting Information). Thus, MAI serves as a protection layer, limiting perovskite decomposition, while the $\mathrm{PbI}_{2}$ surface termination is inherently unstable.

Under ambient conditions, the degradation of $3 \mathrm{D}$ perovskites is known to result in the formation of a $\mathrm{PbI}_{2}$ yellow phase, and X-ray photoelectron spectroscopy (XPS) suggests that it is accompanied by the loss of MAI into the gas phase, with no measurable formation of perovskite hydrate ${ }^{19}$ even in a high-humidity environment. In contrast, simulations predict a greater than $2 \mathrm{eV}$ desorption energy for organic molecules. To reconcile these observations, we included water in our simulations, ${ }^{20}$ and found a significant decrease in desorption energies and decomposition lifetimes (Figure. $1 b$ ), consistent with the sensitivity of perovskite to moisture ${ }^{18,33}$.
Notably, we find that van der Waals interactions between the capping organic molecules are key drivers of increased material stability ${ }^{21}$ : the energy required to remove PEAI from the perovskite is $0.36 \mathrm{eV}$ higher than that for MAI, reducing the desorption rate by six orders of magnitude, and slowing film decomposition onethousand-fold (additional details on DFT simulations and results can be found in Supporting Information).

Motivated by these insights, and building on the previously-reported solvent-engineering fabrication process ${ }^{22}$, we fabricated dimensionally-tuned perovskite films using single-step spin-coating. X-ray diffraction (XRD) patterns for the $3 \mathrm{D}$ and quasi-2D perovskite thin films show very similar reflections, indicating a preferential orientation of the crystallites relative to the substrate. Thus, thin film samples do not exhibit Bragg reflections at low diffraction angles $2 \theta^{\circ}$, yet these low-diffraction-angle features represent the unambiguous signatures of the layered structure, specifically of the elongated unit cell ${ }^{23}$.

We therefore obtained powders from the films that would lack preferential orientation. These powder samples show diffraction scans that, in all but the $3 \mathrm{D}$ case $(n=$ $\infty)$, exhibit a series of Bragg peaks at low angles $(2 \theta$ $\left.<10^{\circ}\right)^{24}$. The XRD data confirm the formation of lead iodide $n$-layer perovskite sheets (Figure. 2a), but are not conclusive on the phase purity of quasi-2D films. Consequently, we embarked on a study of the phase composition of dimensionally-tuned perovskite solids of various $n$. 
a

\section{b}
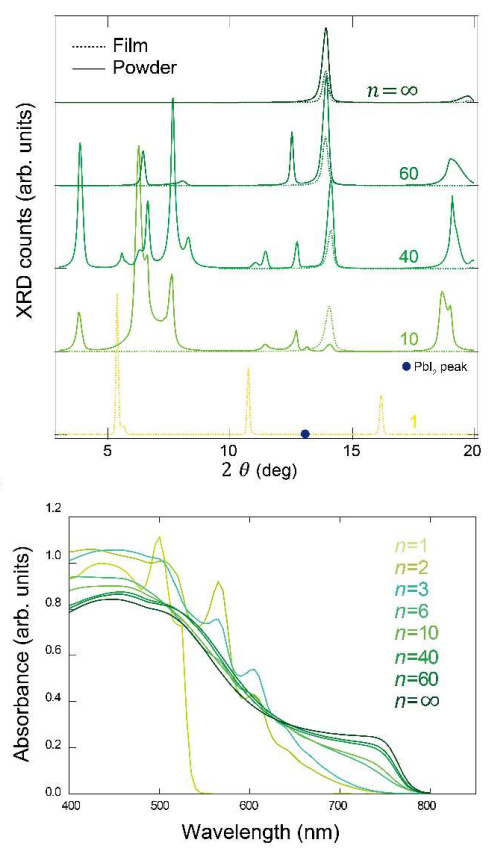
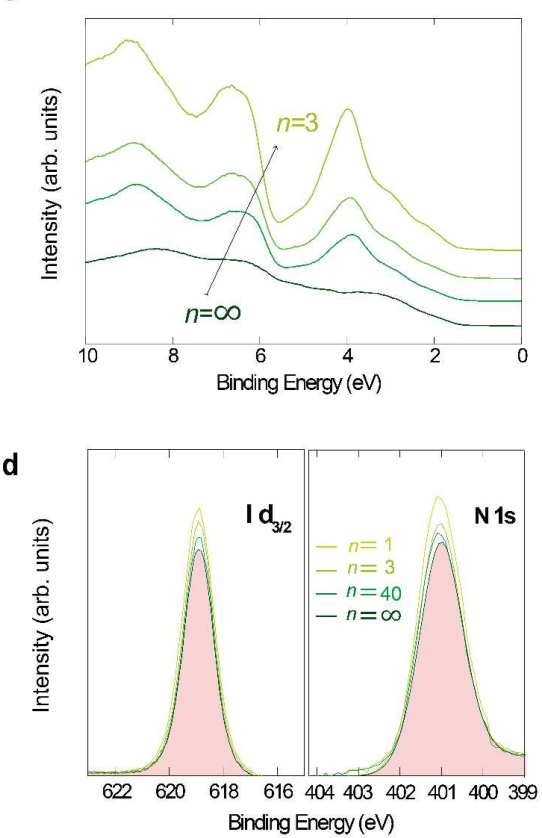

Figure 2. Structure and optical characterization of dimensionally-tuned perovskite films. (a) Low diffraction angle region of XRD spectra. (b) Absorption spectra of the perovskite films with different $n$ values. (c) Valence band photoemission. (d) XPS \begin{tabular}{llllll} 
data & for & the & atomic & core-level & peaks. \\
\hline
\end{tabular}

As expected, decreasing the dimensionality of the perovskite structure causes an increase in the electronic bandgap ${ }^{30,31}$. The dimensional tuning of the electronic bandgap, $\mathrm{E}_{\mathrm{G}}$, can be followed from the absorption spectra (Figure. 2b), which show a higher-energy absorption edge for lower $n$ values. The trend is in good agreement with DFT calculations (Figure. S3). The energy levels of these compounds have been analyzed using a combination of ultraviolet photoemission spectroscopy (UPS) and UV-Vis absorption spectra, as shown in Figure. 2c. The valence band maximum (VBM) for ${ }_{3} \mathrm{D} \mathrm{CH}_{3} \mathrm{NH}_{3} \mathrm{PbI}_{3}$ perovskite is found $5.34 \mathrm{eV}$ below the vacuum level. From this and the optical bandgap, we conclude that the conduction band minimum (CBM) is located at $3.77 \mathrm{eV}^{25}$. When we decrease $n$ values, the CBM becomes shallower while the VBM shows a negligible variation (Figure. $2 \mathrm{c}$ ). The stoichiometry of these perovskite films was verified using Xray photoelectron spectroscopy (XPS) (Figure. 2d), and which reveals a gradual decrease of both the $\mathrm{I}: \mathrm{Pb}$ and $\mathrm{N}: \mathrm{Pb}$ ratios throughout the film with increasing $n$ values, in good agreement with the values expected from the nominal molar ratio of precursors (table $\mathrm{S}$ ). The above studies, taken together, indicate a controlled synthesis of mixed-stoichiometry materials in which the organic cation enables continuous tuning of the dimensionality, and resultant optical properties, of the perovskite compounds.

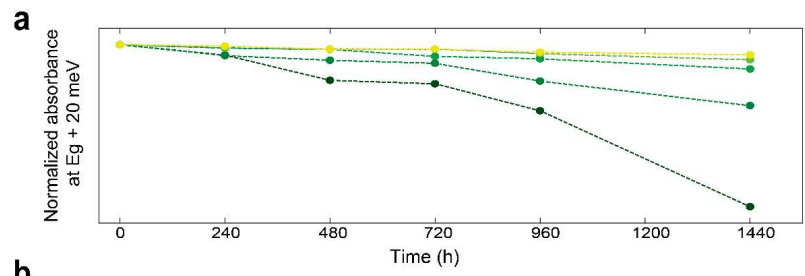

b

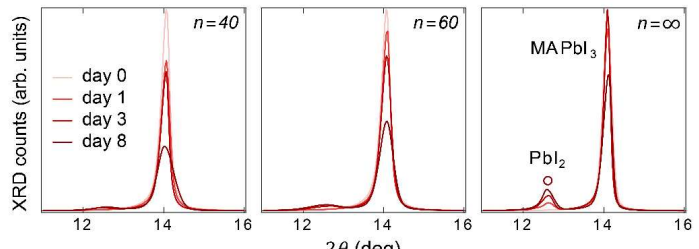

C

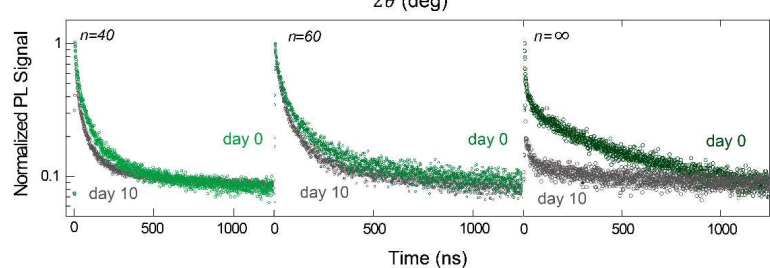

Figure 3. Photophysical and structural stability of $3 \mathrm{D}$ and quasi-2D perovskite films. (a) Relative absorption intensity near the absorption onset for different $n$ values. (b) Film XRD spectra as a function of $n$ at high humidity level (90\%) with different aging time. (c) PL-decay data before and after 10 days storage.

We then investigated material stability as a function of dimensionality. The perovskite films were stored for extended periods of time in environments having controlled humidity levels. In the case of bulk $\mathrm{MAPbI}_{3}$ perovskites, the absorbance (Figure. 3a) near the absorption edge onset degrades rapidly over two months when the sample is 
stored in $90 \%$ relative humidity $(\mathrm{RH})$. After two months, the absorbance of $3 \mathrm{D}$ perovskite films at wavelengths longer than $500 \mathrm{~nm}$ is significantly suppressed, signaling full reversion to $\mathrm{PbI}_{2}$. In contrast, the pure $2 \mathrm{D}$ perovskite $(n=1), \mathrm{PEA}_{2} \mathrm{PbI}_{4}$, exhibits excellent stability over the same period of time using the same measures, with no ostensible variation in the absorbance observed, which is in good agreement with previous reports ${ }^{16}$. As expected, the quasi$2 \mathrm{D}$ perovskites $(n=10,40,60)$ exhibit significantly improved stability compared to $3 \mathrm{D}$ perovskite. A slight change in the absorbance is observed for the prominent perovskite peak around $750 \mathrm{~nm}$, suggesting that a part of these perovskite films has converted to $\mathrm{PbI}_{2}$ (Figure. 3a). Layered perovskites with lower $n$ value $(n=10)$ (i.e. closer to $2 \mathrm{D}$ ) are found to exhibit better stability of optical properties compared to higher $n$ values $(n=40,60)$.

We tracked the materials structure stability using XRD periodically recorded on perovskite films stored at $90 \%$ $\mathrm{RH}$ for more than a week (Figure. 3b). Strong (oo2) diffraction peaks (at $2 \theta=13.98^{\circ}$ ) characteristic of the perov- skite structure are observed for all fresh samples. However, a new peak at $2 \theta=12.42^{\circ}$ emerges for $3 \mathrm{D}$ perovskite film, corresponding to a Bragg reflection of $\mathrm{PbI}_{2}$ structure, with an increasing intensity over time. In contrast, only a very weak $\mathrm{PbI}_{2}$ reflection appears in the $n=60$ and $n=40$ perovskite films with a peak intensity nearly unchanged over the same period of time, which indicate a significant improvement of stability compared to $3 \mathrm{D}$ perovskite.

We also investigated the materials' stability using transient photoluminescence (PL) decay measurements. We then tracked any changes over time (Figure. 3c). Dramatic changes are observed in the PL-decay traces for the ${ }_{3} \mathrm{D}$ perovskite after 10 days' storage in air. There is no observable variation in the carrier lifetime of quasi-2D $(n=40$, 6o) perovskites. The PL-decay changes provide further support of enhanced stability: specifically, the lower $n$ valued perovskites exhibit improved stability of PL lifetime compared to higher $n$-values counterparts, a finding that is in good agreement with DFT studies (Figure. 1b) a

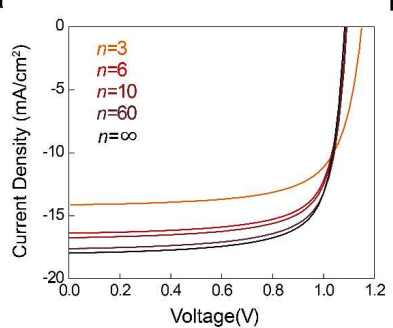

b

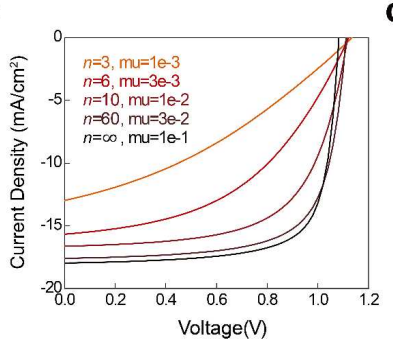

C

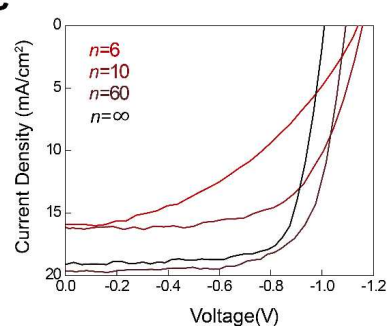

Figure 4. Comparison of $J$ - $V$ curves for different number of perovskite layers. (a) Simulation using experimental absorption spectra and band gaps, and mobility of $0.1 \mathrm{~cm}^{2} \mathrm{~V}^{-1} \mathrm{~s}^{-1}$. (b) Simulation with radiative recombination of $5 \cdot 10^{-10} \mathrm{~cm}^{3} \mathrm{~s}^{-1}$ and gradually decreasing mobility for lower $n$. Same trap density is used for all cases. (Perovskite layer was estimated to be 200 nm thickness). (c) Experimental curves.

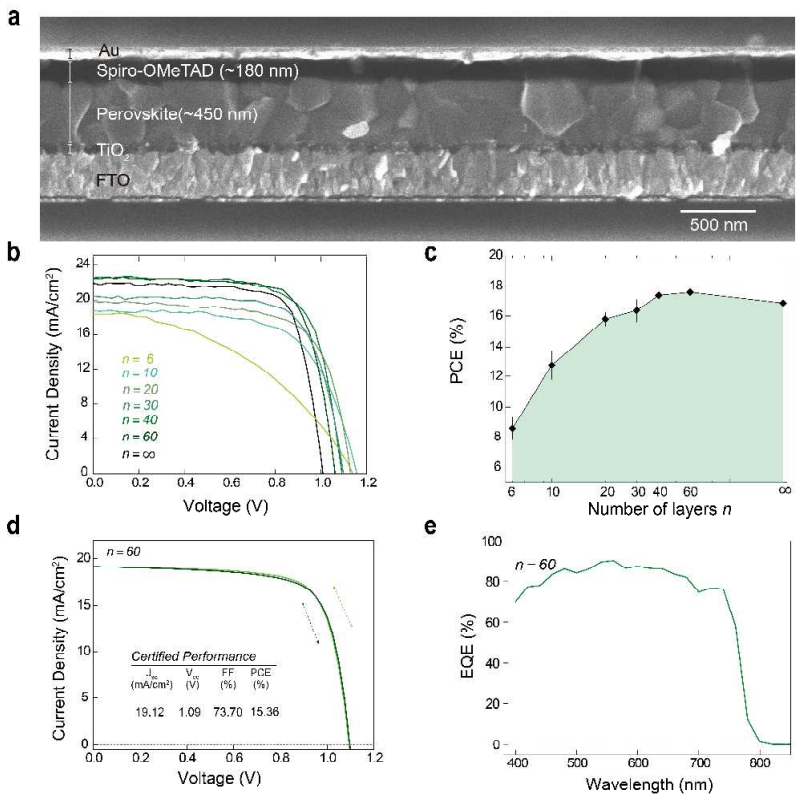

Figure 5. Solar cell device architecture and performance. (a) Cross-sectional scanning electron microscopy (SEM) image for a quasi-2D perovskite device with $n=60$. (b and c) $J$ - $V$ curve and PCEs for champion perovskite device with different $n$ values. (d 
and e) $J$ - $V$ curve, both forward and reverse scan and external quantum efficiency (EQE) spectra of the certified device with $n=60$ perovskite.

We turned to evaluating the enhanced-stability materials for photovoltaic applications. Unfortunately the pure $2 \mathrm{D}$ perovskites $(n=1)$ and low $n$-values quasi-2 $\mathrm{D}$ perovskite films exhibit appreciably reduced mobility $\mu$ and lower lifetime ${ }^{21}$; further, they have a significantly wider bandgap that will sacrifice absorption in the near-infrared (NIR) portion of the solar spectrum. In contrast, our studies of carrier lifetime $\tau$ and carrier diffusion length $\mathrm{LD}^{9}$ (table $\mathrm{S}_{2}$ ) indicated that the quasi-2D perovskite having higher $n$ values $(n=40,60)$ films exhibit impressive $\tau, \mu$, and LD compatible with photovoltaic performance ${ }^{27}$. Since the $3 \mathrm{D}$ perovskite films are limited not by mobility but instead by trap volume density ${ }^{26}$, we reasoned that some sacrifice to mobility in the quasi-2D materials may potentially be tolerable before radiative recombination becomes a considerable loss, an idea confirmed via selfconsistent optoelectronic simulations. Fig. 4 shows a qualitative comparison of simulated and experimental $J-V$ curves. Modeling assuming the same carrier diffusion length of $350 \mathrm{~nm}$ for all samples and using experimental absorption spectra and band gaps (Fig. S4a) cannot reproduce experimental trends (Fig. $\mathrm{S}_{4 \mathrm{C}}$ ): (i) the fill-factor $(F F)$ stays the same for all samples and for low $n$ it is higher than experimental values; (ii) $V_{O C}$ is practically unaltered, following the band gap trends, while experimental $V_{O C}$ is higher for lower $n$; (iii) the changes in absorption are not sufficient to explain the drop of $J_{S C}$ for lower $n$. The fill-factor is primarily defined by the carrier diffusion length, which in turn depends on trap density. However, introducing more traps will lead to deterioration of all parameters, $J_{S C}, F F$, and $V_{O C}$, while experimentally $V_{O C}$ actually increases for lower $n$. The increase of $V_{O C}$ is usually a signature of decreased mobility, since slower carrier extraction allows for more carrier accumulation, and thus, higher $V_{O C}$. Higher carrier accumulation, in turn, increases the chances for carriers to meet and recombine radiatively. Including the radiative recombination, in combination with lower mobility, allows reproducing experimental trends, i.e. decrease in $J_{S C}$ and $F F$ while increasing $V_{O C}$ (Fig. S4b). In sum, weak absorption and higher bandgap are detrimental only for very-low $n$ devices, for $n=6$ and higher the main limiting factor is the reduced mobility, leading to strong radiative recombination losses. This suggests that quasi-2D perovskites, with high $n$ values, may be capable of performance comparable to $3 \mathrm{D}$ materials with increased stability.

We therefore constructed solar cells employing the various active layers in a planar heterojunction architecture (Figure. 5a). Cross-sectional SEM indicates the presence of two uniform layers, a $\mathrm{TiO}_{2}$ layer $(\sim 50 \mathrm{~nm})$ over coated with a dense perovskite absorber $(\sim 450 \mathrm{~nm})$. For the ab- sorber layer, a dense-grained uniform morphology with grain sizes in the range of 100-500 $\mathrm{nm}$ was observed in all samples. The grain size shows a slight reduction with decreasing $n$ value (Figure. $\mathrm{S}_{4}$ ).

The perovskite with $n<40$ shows lower performance due to lower mobility which leads to higher charge accumulation and increased radiative recombination losses, which negatively impacts the fill factor $(F F)$ (Figure. 5 b and c). In addition, perovskite films with dimensionality approaching the $2 \mathrm{D}$ limit $(n<10)$ have a wider bandgap and reduced absorption across the solar spectrum. As expected, devices based on perovskite active layers showing a very low $n$ value $(n=6)$ exhibited very low initial performance in view of their low absorbed photon current and poor carrier transport (Figure. $2 \mathrm{~b}$ and $5 \mathrm{~b}$ ).

The top-performing quasi-2D perovskite $(n=60)$ devices exhibited a hysteresis-free certified AM1.5 PCE of 15.3\% (Figure. $5 \mathrm{~d}$ and e). Certification was obtained by an independent photovoltaic calibration laboratory (Figure. $\mathrm{S}_{5}$ ). The steady-state current-density measurement was performed for $3 \mathrm{D}$ and $n=60$ perovskite device (Figure S6). Photocurrent decay during testing of devices was observed in the case of $3 \mathrm{D}$ perovskites; while devices with $n=60$ perovskite showed constant current density over time, consistent with quasi-2D perovskites' low hysteresis. To the best of our knowledge, this is the first report of certified, hysteresis-free planar perovskite solar cells. The introduction of these multilayered perovskite structures might alter the mechanisms of electronic and ionic motion across the film, thus promoting the suppression of the well-known hysteresis in the current-voltage characteristic of planar $3 \mathrm{D}$ perovskite solar cells ${ }^{28}$.

We measured solar cell performance and its evolution in time (Figure. 6a). The $3 \mathrm{D}$ perovskite devices began with 16.6\% PCE but degraded over 8 weeks to less than 3\% PCE when stored in $\mathrm{N}_{2}$. Moderate $n$ value perovskites $(n=10)$ showed improved performance together with good longterm stability (Figure. 6b-e); however, the absolute device performance is still low compared with state of the art perovskite device due to poor carrier transport, which limits their further application.

Most interesting were the quasi-2 $\mathrm{D}$ perovskites, both $n=60$ and $n=40$ (Figure. 6b-e). The performance of the $n=6$ o device declined to $11.3 \%$ PCE after 6 o days under low humidity atmosphere, while the $n=40$ device had a similar initial PCE and declined to $\mathbf{1 3 . 1} \%$ after 60 days (tables $\mathrm{S}_{4}$ to S8). Longer-term stabilization is expected when a physical moisture barrier such as a carbon electrode is deployed into the device architecture, combined with use of quasi-2D perovskites $(n=60,40)^{12}$. 


\section{a}
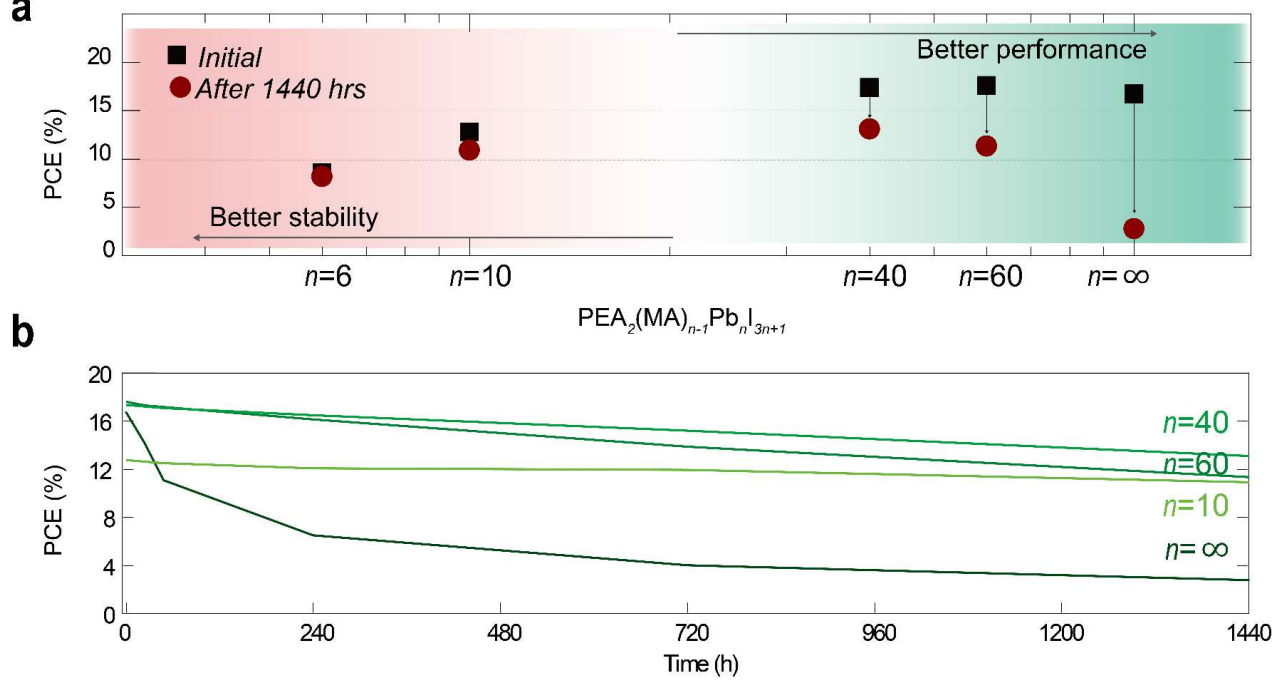

C

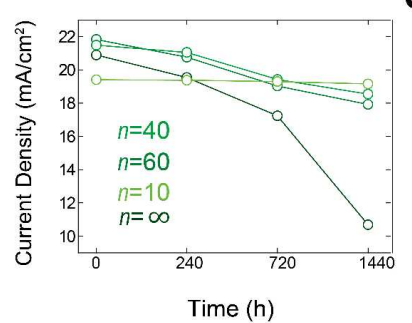

d

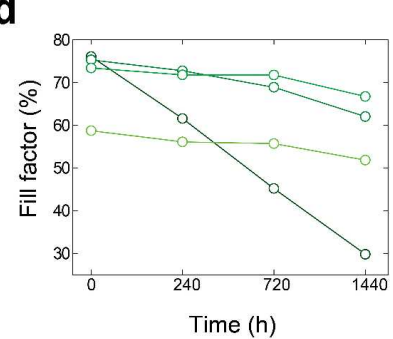

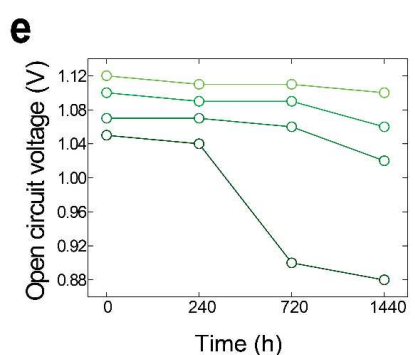

Figure 6. Solar cell device stability. (a) The device performance as a function of $n$ value, which shows increased performance was achieved with increased $n$ value, however, at the meantime, stability was decreased. (b) The evolution of device performance as a function of time with different $n$ values. Record of current density (c), fill factor (d) and open circuit voltage (e) change for

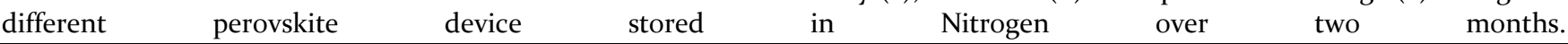

In analogous studies under humid air $(55 \% \mathrm{RH})$, the $3 \mathrm{D}$ perovskite lost the majority of its performance, decreasing to $4.2 \%$ PCE in 3 days. In contrast, over two weeks under high $\mathrm{RH}$, the $n=60$ and $n=40$ devices decreased to about $13 \%$ PCE in each case (table S8). Statistical data on the decay of performance were summarized in Supporting Information (Figure. S7). The thermal stability of devices was evaluated by annealing at $100{ }^{\circ} \mathrm{C}$ for $36 \mathrm{hr}$ (Figure. S8). The PCE of the device with $n=60$ perovskite showed a modest improvement in thermal stability compared with the $3 \mathrm{D}$ perovskite devices.

In sum, the very low formation energy of $3 \mathrm{D}$ perovskites accounts for their low stability relative to their precursor phases. This problem is exacerbated by water and humidity. We show herein using that adding an organic molecule that does not incorporate into the $3 \mathrm{D}$ lattice can be used to produce capped-layered quasi-2 $\mathrm{D}$ perovskitebased materials; and that these possess much higher formation energies, owing to appreciable van der Waals forces that confer improved stability. By replacing the methylammonium (MA) with the formamidinium $\left(\mathrm{HN}=\mathrm{CHNH}_{3}{ }^{+}, \mathrm{FA}\right)$ cation to further reduced quasi-2D perovskites' bandgap, solar devices with even higher performance without hysteresis could potentially be engineered in the future ${ }^{10}$. The present work suggests that, with further progress, the benefits of perovskites - in long diffusion length for high current and fill factor, as well as low trap state density for high voltage - may be incorporated into more robust solar cells.

\section{EXPERIMENTAL SECTION.}

Phenylethylammonium Iodide Synthesis. Phenylethylamine (10 $\mathrm{mL}, 80 \mathrm{mmol}$ ) was dissolved in $10 \mathrm{~mL}$ of ethanol in an ice bath, and $\mathrm{HI}$ aqueous solution $(55 \%, 20$ $\mathrm{mL}, 17 \mathrm{O} \mathrm{mmol}$ ) was added dropwise to the flask with vigorous stirring. After the addition of HI, the mixture was allowed to stand in ice bath for another 20 minutes until a colorless precipitate appeared. The precipitate was filtered under vacuum and washed thoroughly using cold diethyl ether. The crude precipitate was collected and recrystallized in ethanol twice to obtain thin, plate-like white crystal (16.5g, yield 83\%) EI-MS: m/z 249.2, cacld 249.0.

Film Fabrication. The series of different dimensional perovskite $\left[\left(\mathrm{C}_{6} \mathrm{H}_{5} \mathrm{C}_{2} \mathrm{H}_{4} \mathrm{NH}_{3}\right)_{2}\left(\mathrm{CH}_{3} \mathrm{NH}_{3}\right)_{\mathrm{n}-1} \mathrm{~Pb}_{\mathrm{n}} \mathrm{I}_{3 \mathrm{n}+1}\right]$ solution were prepared by dissolving specific stoichiometric quantities of lead iodide $\left(\mathrm{PbI}_{2}\right)$, methylammonium idodide (MAI) and phenylethylammonium iodide (PEAI) in DMF $(n<10)$ or $\gamma$-butyrolactone / DMSO (5:5, volume ratio) mixture $(n \geq 10)$ at $60{ }^{\circ} \mathrm{C}$ for 12 hours with vigorous stirring. The resulting solution was filtered by PTFE syringe filter $(0.2 \mu \mathrm{m})$ before deposition. The DMF solution $(n<10)$ was then deposited onto the substrate by a singlestep spin-coating process at 5000 r.p.m. for 30 seconds. 
The mixed $\gamma$-butyrolactone / DMSO solution $(n \geq 10)$ was coated onto the substrate via a consecutive two-step spin coating process at 1000 r.p.m. and 5000 r.p.m. for 10 and 60 seconds, respectively. During the second spin step, 100 $\mu \mathrm{L}$ of chlorobenzene were deposited onto the substrate. The resulting films were then annealed at $100{ }^{\circ} \mathrm{C}$ for 1 hour for better crystallization.

Photovoltaic Device Fabrication. A dense compact $\mathrm{TiO}_{2}$ electron transport layer (50 $\mathrm{nm}$ ) was deposited onto a F-doped $\mathrm{SnO}_{2}$ (FTO, Pilkington, TEC 15) substrate, followed by drying at 130 으 for 10 minutes and calcining at $500 \stackrel{\circ}{ } \mathrm{C}$ for 1 hour. The $\mathrm{TiO}_{2}$ precursor solution was prepared by dissolving $890 \mathrm{mg}$ titanium isopropoxide (TTIP) and $30 \mathrm{mg} \mathrm{HCl}$ (37\%) solution in $8 \mathrm{~mL}$ ethanol; the mixture was then stirred at room temperature for overnight before use. The resulting $\mathrm{TiO}_{2}$ film was then immersed in $120 \mathrm{mM}$ of $\mathrm{TiCl}_{4}$ aqueous solution at $70{ }^{\circ} \mathrm{C}$ for 1 hour, then calcined at $500{ }^{\circ} \mathrm{C}$ for another 30 minutes. Then the perovskite absorber was deposited onto the $\mathrm{TiO}_{2}$ using the method described before. The hole-transport layer was spin-coated onto the perovskite film at 4000 r.p.m. for 30 seconds using a chlorobenzene solution that containing of $63 \mathrm{mg} / \mathrm{ml}$ of spiro-OMeTAD and $20 \mu \mathrm{L}$ of tertbutylpyridine, as well as $70 \mu \mathrm{L}$ of bis(trifluoromethane)sulfonimide lithium salt $(170 \mathrm{mg} / \mathrm{mL}$ in acetonitrile). Top electrodes were deposited using an Angstrom Engineering deposition system in an Innovative Technology glovebox. The contacts consisted of $100 \mathrm{~nm}$ electronbeam deposited gold deposited at $0.4 \AA$ Ås.

Relative Humidity Control. For all characterization, the perovskite films were stored at room temperature (measured as $25 \pm 1^{\circ} \mathrm{C}$ ) in the controlled humidity desiccator. The relative humidity $(\mathrm{RH}=90 \%)$ was achieved with an accuracy of $\pm 3 \%$ by a water/glycerol solution with careful adjustment of the weight ratio of glycerol. The precise relative humidity was measured periodically using a calibrated hygrometer.

Photovoltaic Performance Characterization. The steady-state open-circuit voltage, $V_{O C}$, is first measured using the Keithley 2400 by fixing the current to zero and sampling the voltage at multiple time points. The steadystate short-circuit current, $J_{S C}$, is measured by setting the bias voltage to zero and sampling the current at multiple time points. Instantaneous $J$ - $V$ curves are then measured with a scanning rate of $0.02 \mathrm{~V} \mathrm{~s}^{-1}$. The maximum power point $\left(V_{M P P}\right)$ is determined from the instantaneous $J-V$ curve. The steady-state power conversion efficiency, PCE, is measured by setting the bias voltage to the estimated $V_{M P P}$. Under the bias of $V_{M P P}$, the current density value is sampled during 15 seconds to obtain $J_{M P P}$. The PCE is finally obtained as the product of $V_{M P P}$ and $J_{M P P}$. The active area is determined by the aperture before the solar cell to avoid overestimating the photocurrent. Through this aperture (area $0.049 \mathrm{~cm}^{2}$ ) illumination intensity was calibrated using a Melles-Griot broadband power meter and set to be 1 sun $\left(100 \mathrm{~mW} \mathrm{~cm}^{-2}\right)$. The AM 1.5 solar power is supplied by a class A (<25\% spectral mismatch) solar simulator (Science Tech). The spectral mismatch of the system was characterized using a calibrated reference solar cell (Newport). The accuracy of the power measurement was estimated to be $\pm 5 \%$.

UPS Measurements. UPS measurements were carried out in an ultrahigh vacuum chamber (UHV) with a base pressure below $5 \mathrm{X10}^{-9}$ mbar. The photon line width is $\sim 250$ meV and the minimum spot size $\sim 1 \mathrm{~mm}$. He I photons $(21.2 \mathrm{eV})$ were used to acquire the spectra at normal emission. The photoelectrons were collected by the SPHERA $\mathrm{U}_{7}$ hemispherical energy analyzer with a 7 channel MCD detector, in Constant Analyzer Energy (CAE) mode. The binding energy values shown with $10 \mathrm{meV}$ precision should be rounded to the nearest $100 \mathrm{meV}$ value in accordance with the overall energy resolution.

XPS Measurements. XPS measurements were carried out in a Thermo Scientific K-Alpha system, with a $300 \mu \mathrm{m}$ spot size, $75 \mathrm{eV}$ pass energy, and energy steps of $0.05 \mathrm{eV}$. All signals are normalized to $\mathrm{Pb}$ for direct comparison between different samples.

XRD Measurements. XRD measurements on oriented films were conducted on a Panalytical X'Pert Pro diffractometer with a Bragg-Brentano geometry and PIXCEL 1D detector equipped with a nickel filter. Unoriented scans were collected on powders loaded into a o.1-mm diameter silicon capillary on a Bruker $\mathrm{D}_{8}$ Venture diffractometer using monochromated Mo K $\alpha_{1}(0.71073 \AA)$ radiation.

Other Characterizations. The EQE spectrum for photovoltaic device is obtained using a previously published process $^{32}$. Samples are tested in $\mathrm{N}_{2}$ ambient. Photoluminescence (PL) was measured using a Horiba Fluorolog Time Correlated Single Photon Counting system with photomultiplier tube detectors. For steady-state measurements, the excitation source is a monochromatized Xe lamp. For time-resolved PL, the excitation source is a laser diode with a wavelength $t=375 \mathrm{~nm}$; the combined

(source + instrumental response function) time resolution is $\mathrm{il}-0.13 \mathrm{~ns}$.

\section{ASSOCIATED CONTENT}

\section{Supporting Information.}

Materials and methods, additional results, discussion, and references. This material is available free of charge via the Internet at http://pubs.acs.org."

\section{AUTHOR INFORMATION}

\section{Corresponding Author}

*ted.sargent@utoronto.ca (EHS);dhkim@ewha.ac.kr (DHK)

\section{Author Contributions}

$\dagger$ L. N. Q and M. Y contributed equally.

\section{ACKNOWLEDGMENTS}

This publication is based in part on work supported by Award KUS-11-009-21, made by King Abdullah University of Science and Technology (KAUST), by the Ontario Research Fund Research Excellence Program, and by the Natural Sciences and Engineering Research Council (NSERC) of Canada. 
L. N. Quan and D. H. Kim acknowledge the financial support by National Research Foundation of Korea Grant funded by the Korean Government (2014R1A2A1Ao9005656; 2015 M1A2A2058365).

The authors thank Dr. X. Lan for assistance in SEM image acquisition, M. Adachi, B. Sutherland, F. Fan, J. Xu, A. Janmohamed for fruitful discussions, and R. Wolowiec and D. Kopilovic for their assistance during the course of study.

\section{REFERENCES}

(1) Burschka, J.; Pellet, N.; Moon, S.; Humphry-Baker, R.; Gao, P.; Nazeeruddin, M.; Grätzel, M. Nature. 2013, 499, 316.

(2) Lee, M. M.; Teuscher, J.; Miyasaka, T.; Murakami, T. N.; Snaith, H. J. Science. 2012, 338, 643.

(3) Kim, H.; Lee,C.; Im, J; Lee, K.; Moehl, T.; Marchioro, A.; Moon, S.; Humphry-Baker, R.; Yum, J.; Moser, J.; Grätzel, M.; Park, N. Sci Rep 2012, 592, 1.

(4) Im, J.; Lee, C.; Lee, J.; Park, S.; Park, N. Nanoscale 2o11, 3, 4088.

(5) Kojima, A.; Teshima, K.; Shirai, Y.; Miyasaka, T. J. Am. Chem. Soc. 2009, 131, 6050

(6) Jeon, N.; Noh, J.; Yang, W.; Kim, Y.; Ryu, S.; Seo, J.; Seok, S. II. Nature. 2015, 517, 476.

(7) Zhou, H.; Chen, Q.; Li, G.; Luo, S.; Song, T.; Duan, H.; Hong, Z.; You, J.; Liu, Y.; Yang, Y. Science. 2014, 345, 542.

(8) Im, J.; Jang, I.; Pellet, N.; Grätzel, M.; Park, N. Nat. Nanotechnol. 2014, 9, 927.

(9) Xing, G.; Mathews, N.; Sun, S.; Lim, S.; Lam, Y.; Grätzel, M.; Mhaisalkar, S.; Sum, T. C. Science. 2013, 342, 344.

(10) Yang, W.; Noh, J.; Jeon, N.; Kim, Y.; Ryu, S.; Seo, J.; Seok, S. II. Science. 2015, 348, 1234.

(11) Buin, A.; Pietsch, P.; Xu, J.; Voznyy, O.; Ip, A.; Comin, R.; Sargent, E. H. Nano Lett. 2014, 14, 6281.

(12) Mei, A.; Li, X.; Liu, L.; Ku, Z.; Liu, T.; Rong, Y.; Xu, M.; Hu, M.; Chen, J.; Yang, Y.; Grätzel, M.; Han, H. Science. 2014, 345, 295.

(13) Smith, I. C.; Hoke, E. T.; Solis-Ibarra, D.; McGhee, M. D.; Karunadasa, H. I. Angew. Chem. Int. Ed. 2014, 126, 11414.

(14) Cao, D. H.; Stoumpos, C. C.; Farha, O. K.; Hupp, J. T.; Kanatzidis, M. G. J. Am. Chem. Soc. 2015, 137, 7843.

(15) Mitzi, D. B.; Field, C. A.; Harrison, T. A.; Guloy, A. M. Nature. 1994, 369, 467.

(16) Mitzi, D. B. Chem. Mater. 1996, 8, 791.

(17) Kieslich, G.; Sun, S.; Cheetham, A. K. Chem. Sci. 2015, 6, 3430 .

(18) Dualeh, A.; Gao, P.; Seok, S. II.; Nazeeruddin, M. K.; Grätzel, M. Chem. Mater. 2014, 26, 6160.

(19) Yang, J.; Siempelkamp, B. D.; Liu, D.; Kelly, T. L. ACS Nano. 2015, 9, 1955.

(20) Frost, J. M.; Butler, K. T.; Brivio, F.; Hendon, C. H.; Schifgaarde, M.; Walsh, A. Nano Lett. 2014, 14, 2584.

(21) Mitzi, D. B.; Medeiros, D. R.; Malenfant, P. R. L. Inorg. Chem. 2002, 41, 2134.

(22) Jeon, N. J.; Noh, J. H.; Kim, Y. C.; Yang, W. S.; Ryu, S.; Seok, S. II. Nat. Mater. 2014, 13, 897.

(23) Heo, J.; Im, S.; Noh, J.; Mandal, T.; Lim, C.; Chang, J.; Lee, Y.; Kim, H.; Sarkar, A.; Nazeeruddin, M.; Gratzel, M.; Seok, S. II. Nat. Photonics. 2013, 7, 486.
(24) Kegan, C. R.; Mitzi, D. B.; Dimitakopoulos, C. D. Science. 1999, 286, 945.

(25) Miller, E. M.; Zhao, Y.; Mercado, C.; Saha, S.; Luther, J.; Zhu, K.; Stevanovic, V.; Perkins, C.; Lagemaat, J. Physical Chemistry Chemical Physics. 2014, 16, 22122.

(26) Tan, Z.; Moghaddam, R.; Lai, M.; Docampo, P.; Higler, R.; Deschler, F.; Price, M.; Sadhanala, A.; Pazos, L.; Hanusch, F.; Bein, T.; Snaith, H. J.; Friend, R. H. Nat. Nanotechnol. 2014, 9, 687 .

(27) Kim, H.; Mora-Sero, I.; Gonzalez-Pedro, V.; FabregatSantiago, F.; Juarez-Perez, E.; Park, N.; Bisquert, J. Nat. Commun. 2013, 4, 2242.

(28) Snaith, H. J.; Abate, A.; Ball, J. M.; Eperon, G. E.; Leijtens, T.; Noel, N. K.; Stranks, S.; Wang, J.; Wojciechowski, K.; Zhang, W. J. Phys. Chem. Lett. 2014, 5, 1511.

(29) Li, X.; Dar, M.; Yi, C.; Luo, J.; Tschumi, M. T.; Zakeeruddin, S. M.; Nazeeruddin, M.; Han, H.; Gratzel, M. Nature Chem. 2015, 7, 703.

(30) Sichert, J.; Tong, Y.; Mutz, N.; Vollmer, N.; Fischer, S; Milowska, K.; Cortadella, R; Nickel, B.; Cardenas-Daw, D.; Stolarczyk, J.; Urban, A.; Feldmann, J. Nano Letters, 2015, 15, 6521

(31) Tyagi, P.; Arveson, S.; Tisdale, W. J. Phys. Chem. Lett. 2015, 6, 1911

(32) Yuan, M.; Zhitomirsky, D.; Adinolfi, V.; Voznyy, O.; Kemp, K.; Ning, Z.; Lan, X.; Kim, J.; Dong, H.; Sargent, E. H. Adv. Mater. 2013, 25, 558.

(33) Christians, J. A.; Miranda Herrera, P. A.; Kamat, P. V. J. Am. Chem. Soc. 2015, 137, 1530. 
Table of content

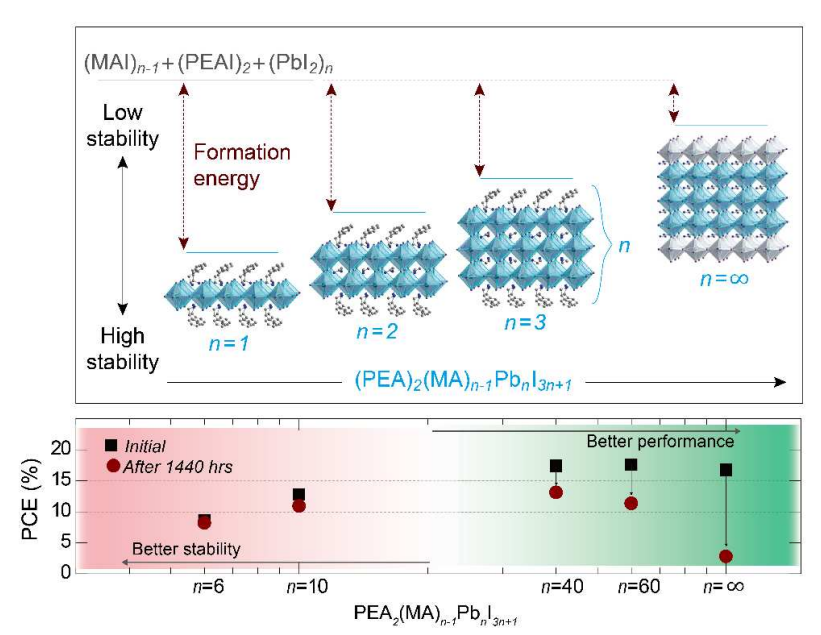

23

24

26

27

30

31

32

33

34

36

37

38

39

40

41

43

44

45

46

47

48

49

51

52

53

54

55 


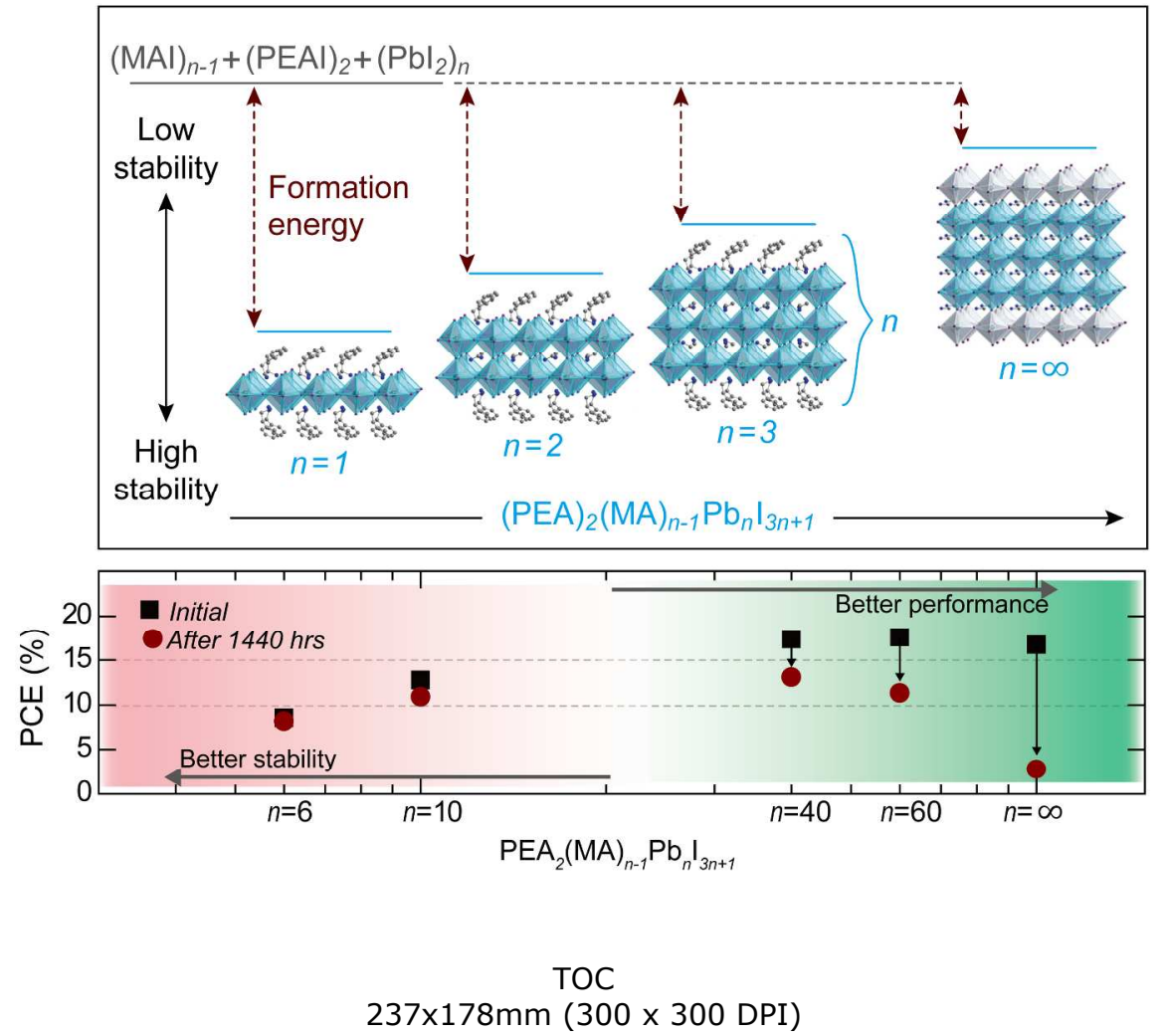

$237 \times 178 m m(300 \times 300$ DPI) 
a

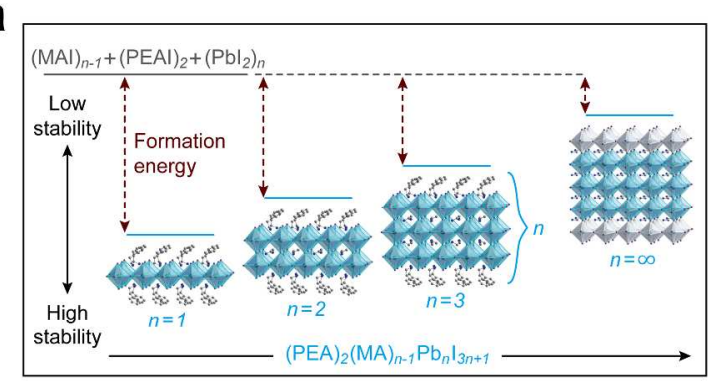

b

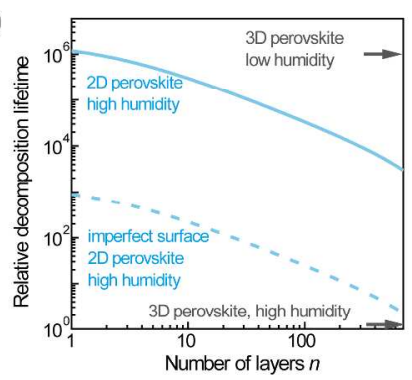

Figure 1. Energetics of perovskite formation and stability. (a) Unit cell structure of (C8H9NH3)2(CH3NH3)n$1 \mathrm{PbnI} 3 n+1$ perov-skites with different $n$ values, showing the evolution of di-mensionality from $2 \mathrm{D}(n=1)$ to 3D $(n=\infty)$. (b) DFT simulation of the formation energy of perovskite with different $n$ values in different atmospheres.

$274 \times 94 \mathrm{~mm}(300 \times 300 \mathrm{DPI})$ 
a

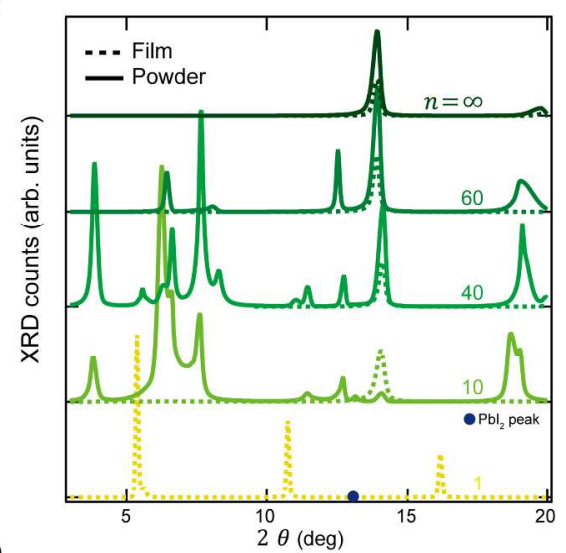

b

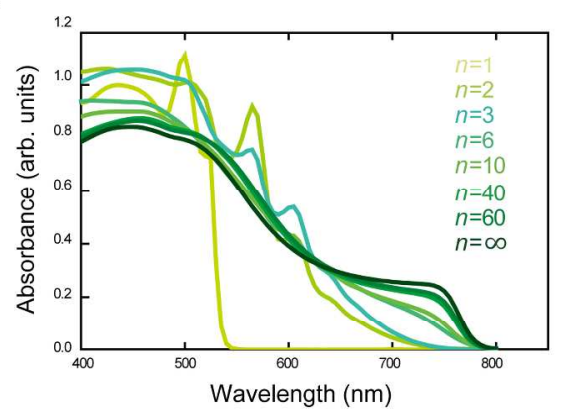

C

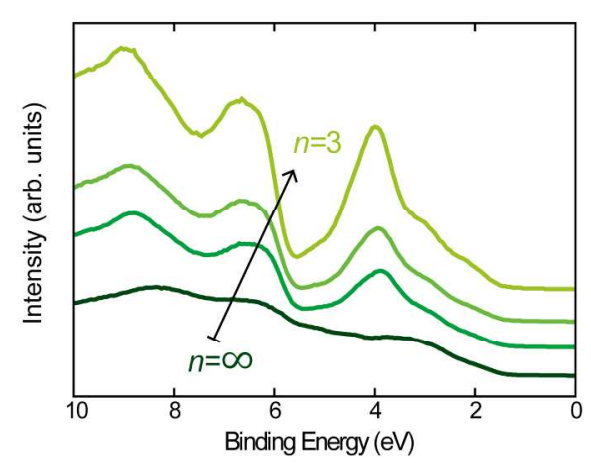

d

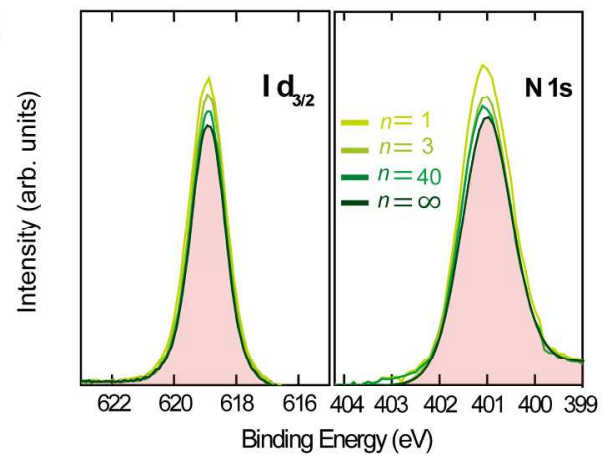

Figure 2. Structure and optical characterization of dimen-sionally-tuned perovskite films. (a) Low diffraction angle region of XRD spectra. (b) Absorption spectra of the perov-skite films with different $n$ values. (c) Valence band photoe-mission. (d) XPS data for the atomic core-level peaks. $214 \times 172 \mathrm{~mm}(300 \times 300 \mathrm{DPI})$ 
Figure 3. Photophysical and structural stability of 3D and quasi-2D perovskite films. (a) Relative absorption intensity near the absorption onset for different $n$ values. (b) Film XRD spectra as a function of $n$ at high humidity level (90\%) with different aging time. (c) PL decay data before and after 10 days storage $213 \times 205 \mathrm{~mm}(300 \times 300 \mathrm{DPI})$ 
a

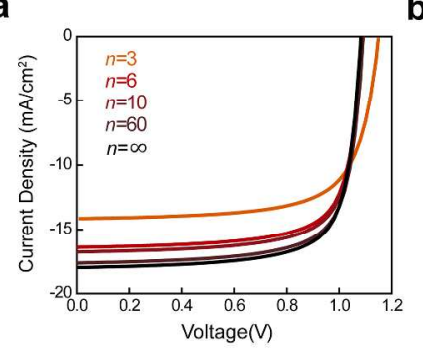

b

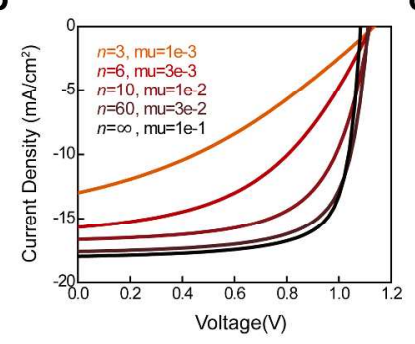

C

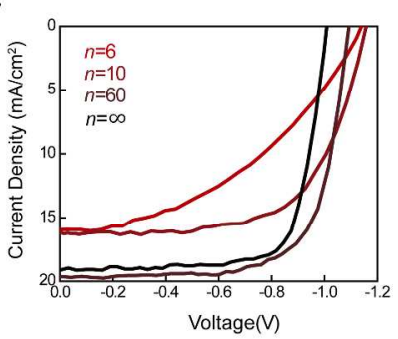

Figure 4. Comparison of J-V curves for different number of perovskite layers. (a) Simulation using experimental absorption spectra and band gaps, and mobility of $0.1 \mathrm{~cm} 2 \mathrm{~V}-1 \mathrm{~s}-1$. (b) Simulation with radiative recombination of $5 \bullet 10-10 \mathrm{~cm} 3 \mathrm{~s}-1$ and gradually decreasing mobility for lower $\mathrm{n}$. Same trap density is used for all cases. (Perovskite layer was estimated to be $200 \mathrm{~nm}$ thickness). (c) Experimental curves.

$261 \times 79 \mathrm{~mm}(300 \times 300 \mathrm{DPI})$ 
Figure 5. Solar cell device architecture and performance. (a) Cross-sectional scanning electron microscopy (SEM) image for a quasi-2D perovskite device with $n=60$. ( $b$ and $c$ ) J-V curve and PCEs for champion perovskite device with differ-ent $n$ values. ( $d$ and e) J-V curve, both forward and reverse scan and external quantum efficiency (EQE) spectra of the certified device with $n=60$ perovskite. 
Figure 6. Solar cell device stability. (a) The device perfor-mance as a function of $n$ value, which shows increased per-formance was achieved with increased $n$ value, however, at the meantime, stability was decreased. (b) The evolution of device performance as a function of time with different $n$ values. (c) Record of JcS, FF and Voc change for different per-ovskite device stored in Nitrogen over two months. $215 \times 179 \mathrm{~mm}(300 \times 300$ DPI $)$

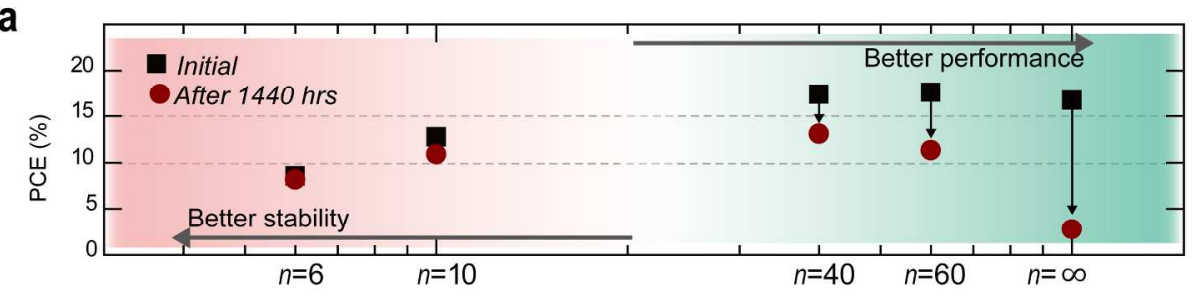

b

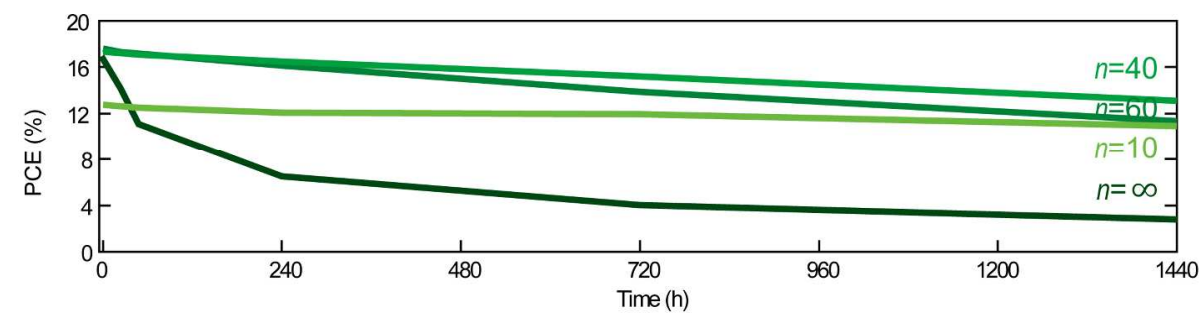

C

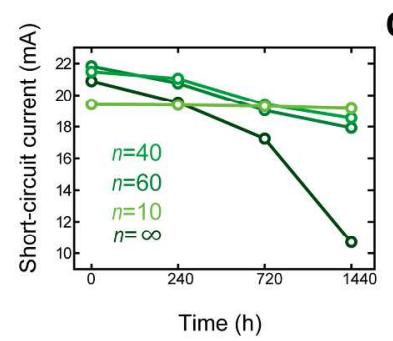

d

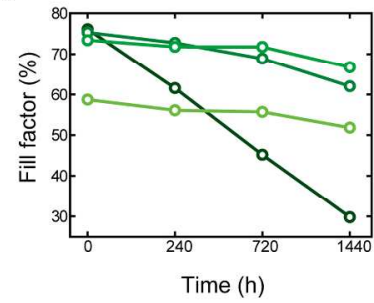

e

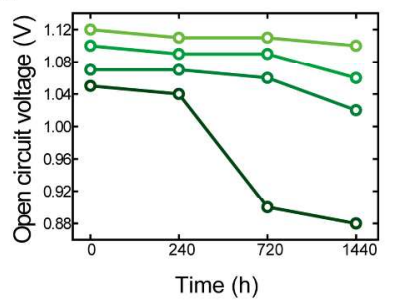

